(Version JPLPH)

\title{
Responses of seminal wheat seedling roots to soil water deficits
}

\author{
Carlos Trejo ${ }^{a, c}$, Mark A Else ${ }^{b}$, Christopher J Atkinson ${ }^{c, *}$
}

\begin{abstract}
aPosgrado en Botánica, Colegio de Postgraduados, Carretera México-Texcoco, Montecillo Estado de México CP. 56230, México bNIAB EMR, New Road, East Malling ME19 6BJ, UK

cUniversity of Greenwich, Natural Resources Institute, Central Avenue, Chatham Maritime, ME4 4TB, UK

*Corresponding author.

E-mail addresses: catre@colpos.mx (C Trejo López), Staff.Else@emr.ac.uk (MA Else) c.j.atkinson@gre.ac.uk) (CJ Atkinson)
\end{abstract}

Keywords:

Abscisic acid

Ethylene

Seminar roots

Soil water deficits

Wheat

Word count: 7757

Tables 3

Figures 8 


\section{Summary}

The aims of this paper are to develop our understanding of the ways by which soil water deficits influence early wheat root growth responses, particularly how seminal roots respond to soil drying and the extent to which information on differences in soil water content are conveyed to the shoot and their impact on shoot behaviour. To achieve this, wheat seedlings have been grown, individually for around 25 days after germination in segmented soil columns within vertical plastic compartments. Roots were exposed to different soil volumetric moisture contents (SVMC) within the two compartments. Experiments where the soil in the lower compartment was allowed to dry to different extents, while the upper was maintained close to field capacity, showed that wheat seedlings allocated proportionally more root dry matter to the lower drier soil compartment. The total production of root, irrespective of the upper or lower SVMC, was similar and there were no detected effects on leaf growth rate or gas exchange. The response of seminal roots to proportionally increase their allocation of dry matter, to the drier soil was unexpected with such plasticity of roots system development traditionally linked to heterogeneous nutrient distribution than accessing soil water. In experiments where the upper soil compartment was allowed to dry, root growth slowed and leaf growth and gas exchange declined. Subsequent experiments used root growth rates to determine when seminal root tips first came into contact with drying soil, with the intentions of determining how the observed root growth rates were maintained as an explanation for the observed changes in root allocation. Measurements of seminal root $A B A$ and ethylene from roots within the drying soil are interpreted with respect to what is known about the physiological control of root growth in drying soil. 


\section{Introduction}

Nine billion people will have to be fed by the middle of this century (Godfray et al., 2010; Tomlinson 2013). To achieve the necessary increase in food production, in a sustainable manner, requires that we utilise resources more efficiently and avoid bringing more land into agricultural production (Royal Society, 2009). The implications are that agricultural systems will have to sustain the productivity of current land and not exploit further forested areas, or utilise more marginalised regions with problems of water deficit and elevated temperatures (Godfray et al., 2010). Global climate change predictions suggest changes in the amount and patterns of precipitation and so understanding crop water use efficiency, at all levels, is a major task as water availability is one of the main environmental factors limiting development, growth, and the yield of crops (Boyer, 1982; Chaves and Oliveira, 2004). Application of innovation is a key factor in the increase of crop yields, but before this can happen; we need to understand the principles that influence aspects of plant development and growth, which provide the means by which drought tolerance can be achieved.

The root system is the main organ of the plant which absorbs water and nutrients from the soil (Manske and Vlek, 2002). It is, therefore, the first sensor to perceive any change in soil water and nutrient availabilities. The capacity of a root system to absorb water and nutrients is crucial to plant survival (Xu et al., 2003; Wasson et al., 2012; Ren et al., 2012; Renton and Poot, 2014; Jin et al., 2015). It is also a major determinant of crop productivity (Reynolds et al., 2009; White et al., 2015). Evidence suggests that early developmental and growth related characteristics of the root system are a determinant of its reproductive performance (Zhang et al., 1998; Fabian et al., 2008; Lynch, 2011; Ober et al., 2014; Atkinson et al., 2015). It is however surprising that, in general, we have only recently begun to understand the events which determine, either, the architectural pattern, or physiological function, particularly with respect to early root system development and 
its role in the acquisition of water (Nakamoto and Oyanagi, 1994; Manske and Vlek, 2002; Sanguineti et al., 2007; Manschadi et al., 2008; Lynch, 2011; Nakhforoosh et al., 2014; Ji et al., 2014). There are important implications for why we should have a better understanding of early development of roots and how their growth is influenced by environmental stresses such as drought, particularly those likely to be associated with responses to climate change and its impacts on crop production (Nakamoto and Oyanagi, 1994; Zhang et al., 1998; Fabian et al., 2008; Ren et al., 2012; Wasson et al., 2012; Ober et al., 2014). The mechanisms by which roots sense and respond to variations in water availability in the soil are not yet thoroughly understood. The work of Sharp and Davies (1979) showed, in maize, that moderate water deficits provoked a net increase in root growth. Subsequent results, also with maize, demonstrated the differential effects of low water potentials $\left(\psi_{w}\right)$ along the root axis, with the first three millimeters behind the apex being insensitive to low $\psi_{w}$ despite root abscisic acid (ABA) concentration being higher than in well-watered controls (Sharp et al., 1988). Different experimental approaches (ABA-mutants, $A B A$ and ethylene inhibitors) have been used to explain these findings and it is concluded that under drought stress, root $A B A$ concentration increases maintaining low ethylene concentrations which prevent its inhibitory effect on root growth (Sharp, 2002). There is also some support for the involvement of root ABA in the differential control of wheat root and shoot dry matter allocation when subject to nutrient deficiencies (Vysotskaya et al., 2008).

The intentions of this paper are to develop our understanding of the way in which soil water deficits influence newly germinated wheat root growth responses. To achieve this we have developed an experimental system to grow wheat seedlings for around 25 days directly after germination and expose seminal roots to different soil volumetric moisture contents (SVMCs). Our aim is to determine how seminal root (see Nakamoto and Oyangi, 1994) growth responses change 
when they are exposed to stratigraphic differences in SVMCs and how these differences are perceived and influence shoot behaviour. Wheat seminal root growth was quantified over time when newly germinated seedlings were exposed to isolated, but different vertical profiles of SVMCs. We hypothesized that root perception of drying soil is a key component in root behaviour responses and the subsequent pattern of soil exploitation. More specifically, we also question how initial seminal root development, during early crop growth, may be linked physiologically to shoot development and what are the implications for soil water deficits during early crop establishment.

\section{Materials and methods}

\section{Experimental approach}

The system used two polyvinyl-chloride (PVC) compartments, with an external diameter of $80 \mathrm{~mm}$ and a length of $150 \mathrm{~mm}$, which were joined end to end to create two rooting horizons. Both compartments were filled with soil, which was a mixture of three parts of soil ('Barming Series', Fordham and Green, 1980) obtained from a field plot at East Malling and one part of sand (horticulture grade, William Sinclair Horticulture Ltd. UK). Previously both soil and sand were sieved using a $2 \mathrm{~mm}$ diameter sieve. To ensure no water movement by either gravity or capillary rise (from one compartment horizon to another), as well as ensuring the soil in the upper compartment (horizon) did not move, a woven nylon membrane ( $3 \mathrm{~mm}$ mesh) was fixed across the bottom of the upper compartment prior to attaching the lower compartment. The mesh was held firmly in place by a plastic ring inserted within the lower compartment and the surface of the nylon mesh was covered with a layer of petroleum jelly (Vaseline ${ }^{T M}$, ca 2-3 mm thick). This sealed the upper 
compartment ensuring its SVMC had no influence on the lower compartment SVMC. Preliminary experimental observations showed that the presence of neither the nylon mesh, nor the petroleum jelly prevented root penetration or altered the rate at which roots entered the lower compartment. Equally importantly, root tip development was also examined to ensure that the petroleum jelly did not alter root development (tip or elongation), or growth rate into the lower compartment. To validate this experimental approach the SVMC content of the upper compartment was maintained close to full soil water capacity (FSWC, 21-24\%), while the soil in the lower horizon connected compartment, had a SVMC set at $10 \%$. Every other day the SVMC of both compartments was measured in situ (Wet-2 Sensor, Delta-T Devices, Ltd, Cambridge, UK) by inserting the probe through access holes in the side of both compartments at points above and below, but close to the separating layer of petroleum jelly between the two compartments. This validation showed that the experimental system could maintain SVMC in the two compartments when at very different SVMC, for at least $35 \mathrm{~d}$.

Plant material and experimental conditions

Seeds of spring wheat (Triticum aestivum L.) cv. Redigo Mulika previously, treated with a fungicide, were placed on moist tissue paper in plastic Petri dishes and incubated at $20^{\circ} \mathrm{C}$ in the dark for $38 \mathrm{~h}$ prior to germination. Similar sized seedlings were selected based on those which had hypocotyl lengths of 3-5 $\mathrm{mm}$, and three seminal roots of 5-8 $\mathrm{mm}$ in length. These were planted into the upper compartments filled with soil at FSWC (full soil water capacity) with the nylon mesh and petroleum jelly on the bottom. Seedlings were maintained in an ambient lit, temperature-controlled 
greenhouse $\left(20 \pm 5^{\circ} \mathrm{C}\right)$ and after three days the lower compartment was attached, generally, with a SVMC different from the compartment above.

\section{Experiments}

Experiment 1: The aims of this experiment were to grow seedlings at a SVMC, in the upper compartment which was constant (around $21 \%$, equivalent to FSWC), while allowing the SVMC in the lower compartment to decline in a stepwise manner to SVMC around $10 \%$. Six treatments of different SVMC in the lower compartment were used: control (SVMC of $21 \%$ in both compartments) and $18,16,15,14$ and $12 \%$ SVMC in the lower compartment. The entire experiment was repeated on two further occasions in a similar manner.

Experiment 2: The aim of this experiment was to use the same approach as in experiment 1, but grow the seedlings for a shorter period to avoid possible effects induced by roots reaching the bottom of the lower compartment. Again, a range of SVMC was established in the lower compartment (21 to $12 \%$ ), while in the upper compartment SVMC was kept at $21 \%$. Rooting was again measured, at harvest after 18 days of growth, as the distribution of dry matter and root length to both the upper and lower compartments.

Experiment 3: Three different combinations of upper and lower compartment SVMC were established to define and compare seedling capacity to detect a decline in SVMC in either the upper or lower compartment. This was achieved in the following manner: treatment (T24:24), where both the upper and lower compartments were kept close to SVMC of $21 \%$ by watering from the top and the bottom of the compartments. A second treatment (T4.8:24), started with the upper compartment at soil $21 \%$ to which no further water was added after seedling transplantation, while 
the lower compartment was kept close to a SVMC of $21 \%$ by watering from below. For the third treatment (T24:11), the upper compartment was kept close to FSWC, while the lower compartment had a SVMC of about 12\%, similar to experiments 1 and 2 . This approach provide a rooting environment where the SVMC was constant (T24:24), where SVMC closest to the establishing seedling declined (T4.8:24) and (T24:11) where SVMC declined in soil in which seedling roots could grow.

Experiment 4: The aim of this experiment was to establish a precise time course of events when the first seminal root grew out of the upper compartment (wetter) and seminal root tips first made contact with soil in the lower drier compartment (methodology as in experiments 1 and 2). Root distribution was measured in both compartments over a $20 \mathrm{~d}$ period, as changes in the root dry matter and root length allocation, in response to contact with SVMC in the lower compartment of 14,12 or $10 \%$.

Experiment 5: From experiment 4 the timing of root tip growth from the upper compartment at FSWC in to the lower compartment at a lower SVMC was confirmed (previous experiments had made preliminary observations on this event) and used to carry out a highly replicated experiment to link the quantitative data on root development with specific physiological changes in the root at the time when the first seminal root made contact with the lower compartment SVMC. Seminal roots within the lower compartment where analysed for changes in their ABA concentrations and ethylene production rates. To carry out the analysis of roots at the point where they were first in contact with the lower drying soil required a sufficient amount of root mass (e.g. $\sim 0.04 \mathrm{~g}$ fwt for the ethylene, and 5 to 7 roots for the ABA analyses). Roots were sampled simultaneously for measurements of SVMC and soil water potential $\psi_{w}$. These measurements were made when contrasting two different SVMC in the lower compartment of $21 \%$ and $10 \%$. 
In all experiments leaf length was repeatedly, non-destructively, measured daily to calculate changes in leaf growth rate. At the end of each experiment, total leaf area, shoot, and root dry weight per plant were measured after drying to a constant weight. Before drying the roots, total plant root length was also determined using a root length scanner (Comair, Commonwealth Aircraft Corp. Ltd., Melbourne, Australia), or from direct linear measurements. When both seminal and adventitious nodal roots were present these were analysed separately (see Manske and Vlek, 2002). Instantaneous measurements of leaf gas exchange, which included $\mathrm{CO}_{2}$ assimilation $(A)$, leaf stomatal conductance $(g)$, and transpiration rate $(E)$, were made with a portable and open photosynthetic gas exchange system (LI-6400XT; LICOR, Inc., Lincoln, NE, USA). Soil and root $\psi_{w}$ measurements were made using C-30 sample chambers pyschrometers (Wescor Inc. Logan, UT, USA) connected to an eight-channel data logger PSYPRO (Wescor Inc. Logan, UT, USA) following the method described by the manufacturer.

Ethylene production rates were measured as described by Atkinson et al. (2008). Root samples were rapidly weighed and placed into $4 \mathrm{~cm}^{3}$ vials (Chromacol Ltd., UK), and sealed with a screw lids fitted with a PFTE coated silicone rubber septum. For all tissue samples the analysis process started directly after sampling; material was maintained at a constant temperature $\left(20{ }^{\circ} \mathrm{C}\right)$, in the dark, throughout the equilibrium/incubation period. After approximately $30 \mathrm{~min}, 1 \mathrm{~cm}^{3}$ of the headspace was drawn up into a $1 \mathrm{~cm}^{3}$-glass syringe. The sample was then injected into a Pye Unicam PU4500 gas chromatograph fitted with a $1.5 \mathrm{~m}, 1 / 4$ in. o.d. glass column filled with $10 \%$ OV 3 on Chromosorb W, AW, 80 mesh. Water saturated nitrogen was used as the carrier gas and the injector and column were heated to $50{ }^{\circ} \mathrm{C}$, while the detector was heated to $100{ }^{\circ} \mathrm{C}$. Peaks were detected by ionisation in a hydrogen flame. The retention times of the volatile peaks was recorded and related 
to standards. The peak heights were measured manually and used to estimate the concentrations of ethylene in the vial gas volume.

Abscisic acid (ABA) concentrations in seminal root segments were measured as follows. Quantification was carried out after the addition of deuterated internal standards, ABA was extracted and purified using anion exchange (SAX) (Isolute IST Ltd, UK) and $\mathrm{C}_{18}$ 'Sep-Pak' cartridges (Waters Associates, USA). Following derivatisation with ethereal diazomethane, methyl esters of ABA were quantified using an Agilent 6890 gas chromatogram equipped with a split/splitless injector coupled to an Agilent 5973 mass selective detector (MSD). Concentrations of ABA were computed from calibration curves relating molar ratios of the endogenous compound and its deuterated analogue to ion intensities of their respective molecular ions.

\section{Experimental design and statistical analysis}

All treatments, in all experiments, were distributed in a completed randomized design with a minimum of six replicates for experiments 1 to 4 and 12 for experiment 5 . The data were analyzed using the GLM procedure of SAS software, version 8.2 (SAS Institute, NC, USA) and significant differences between treatments means were separated with Tukey's honestly significant difference (HSD) tests with $P=0.05$. Independence, normality and variance homogeneity test were conducted prior to the analysis of variance using Ryan-Joiner and Bartlett tests, respectively; for cases in which the hypothesis was rejected, the data set was transformed using Johnson transformation (Chou et al., 1998), or a parametric test was performed (Kruskal-Wallis). SigmaPlot software, version 12.3 (SPSS Inc., England) was used to present the graphics.

\section{Results}




\section{Experiment 1}

Over 30 days from germination total seedling leaf area showed no significant decline in response to a reduction in SVMC of $15 \%$ in the lower compartment (data not shown). Calculated leaf relative growth rates $\left(\mathrm{cm} \mathrm{cm}^{-1}\right)$, derived from leaf lengths, for all leaves up to the $5^{\text {th }}$ emerged and $6^{\text {th }}$ emerging leaves showed no significant differences with respect to the declining SVMC in the lower compartment (Figure 1). Equally, there were no significant differences in leaf gas exchange rates $\left(A, 32-34 \mu \mathrm{mol} \mathrm{m} \mathrm{m}^{-2} ; g, 160 \mathrm{mmol} \mathrm{m}^{-2} \mathrm{~s}^{-1}\right.$ and $\left.E, 4.8-5 \mathrm{mmol} \mathrm{m}^{-2} \mathrm{~s}^{-1}\right)$ recorded between any treatment, throughout the experiment. Measurements of total root dry matter production and allocation were carried out by carefully extracting the soil from both compartments and collecting and washing roots to determine dry matter allocation to the upper and lower compartments (Figure 2). This analysis showed that the amount of root allocated to the upper compartment, at a SVMC of $20 \%$, declined, significantly, and proportionally in response to a reduction in SVMC in the lower compartment. The dry matter allocated to the lower compartment increased in response to the declining SVMC in the lower compartment. The total root biomass per plant, summed from the upper and lower compartments, did not vary greatly (i.e. means of $0.617,0.593,0.561,0.637,0.587$ and 0.555 g, respectively, for treatments 20-20 to 20-10), or systematically, in response to different SVMC of the lower compartment.

\section{Experiment 2}

Again, as in Experiment 1, the imposition of a declining SVMC in the lower compartments had no influence on leaf length, leaf growth rate, or leaf gas exchange over the $18 \mathrm{~d}$ of the experiment (data not shown). Measurement of the allocation of dry matter to roots in the upper and lower compartments with their different SVMC showed treatment differences (Figure 3). As with 
experiment 1 root production in the upper compartment was greatest at the highest SVMC (20\%) and this declined as the SVMC in the lower compartment declined. Differences in the allocation to roots for the two compartments were significant with respect to treatment, for the measurement of dry matter, but not for root length. Again, the total amount of root produced per seedlings was similar when the upper and lower compartments were combined, ranging from 0.62 to $0.55 \mathrm{~g}$ per plant, but the allocation of dry matter to roots in the lower compartment, in the drying soil, increased proportionally and sequentially from $25.5 \%$ to $44.9 \%$ with treatment.

\section{Experiment 3}

To complement the results from Experiments 1 and 2, the direct local effects of a reduction in SVMC was made by determining the effects of having a lower SVMC (4.8\%) in the upper compartment relative to the lower compartment SVMC (24\%), i.e. T4.8:24, compared with treatments where SVMC was either the same in the upper and lower compartments (at $24 \%$ ), i.e. T24:24, or at $24 \%$ in the upper and $11 \%$ in the lower (T24:11). As seen in experiment 1 and 2 the seedlings had proportionally more of their roots in the lower compartment when the SVMC was lower, i.e. T24:11 (Figure 4). When the SVMC in the upper compartment was set at 4.8\% (T4.8:24) with the lower compartment at $24 \%$, root distribution was greater in the lower compartment and less in the upper compartment compared with T24:24 and T24:11. This pattern of allocation was consistent, irrespective of root dry matter or root length being quantified. With respect to the total mean root dry weight per plant T24:24 (0.114 g) was similar to T24:11 (0.123 g), while T4.8:24 was lower (0.061 g) (data not shown). The total root dry matter of the T4.8:24 treatment did not include the presence of nodal roots as with the other treatments. The proportional allocation of total root dry matter to the lower compartment also differed with treatment, with T24:24 having 6\% and 
T4.8:24 and T24:11 having 34 and 26\% respectively. Measurements of leaf length, leaf growth rates and leaf gas exchange showed that the drier soil in the upper compartment of T4.8:24 was linked to reduced gas exchange and leaf growth and this was apparent by day 8 , as reduced growth for leaf 2 and then more significantly with leaf 3, while leaf 4 emerged later than its counterparts in T24:24 and T24:11 (Figure 5).

\section{Experiment 4}

From the experience and knowledge gained in earlier experiments root growth was consistent enough to enable accurate predictions of the timing when roots first grew into the lower compartment i.e. on day 6-7 of the $20 \mathrm{~d}$ since transplanting (Figure 6). This information was used to quantify the timing of root development and to determine precisely when, in this experimental protocol, seminal root tips would first experience the SVMC conditions of the lower compartment. This experiment used SVMC of $20 \%$ in the upper compartment while the lower compartment had SVMCs of 14,12 or $10 \%$. Firstly as seen with all the experiments where the SVMC was lower in the lower compartment the allocation of root dry matter, or root length was greater than that in soil with a higher SVMC in the lower compartment. There were no significant treatment differences in root dry matter, or root length in the upper compartment (Figure 6). The time sequence of analyses showed that no roots, irrespective of treatment, had reached the lower compartment by day 5, while by day 11 all treatments had some seminal roots in the soil within the lower compartment, albeit, in different amounts. The analysis showed that roots in the lower compartments at higher SVMC (24 and 14\%) were allocated less carbon while maintaining similar total root lengths. From day 5 to day 20 SVMC and root $\psi_{w}$ where recorded destructively using samples taken from the lower compartment. The results show marked treatment difference in SVMC and root $\psi_{w}$, and how rapidly 
the different treatments with respect to different $\operatorname{SVMC}(21,14,12$, and $10 \%)$ were established and how consistent they were over the 10 days in which roots grew from the upper compartment into the lower compartment (Figure 7).

\section{Experiment 5}

As shown in Experiment 4, roots began to grow into the lower compartment around day 7 to 8 and differences were found between the control (21\%) and the lower drying compartment around day 9 (Figure 8). This treatment difference increased, particularly when measurements supported by root length rather than root dry matter were compared (Figure 8). An analysis of the relationship between root length and root dry weight was also investigated using data from this experiment (data not shown). This analysis showed that there was a linear relationship between root length and root dry matter for the 20\% SVMC $\left(y=3^{-5} x, r^{2} 0.84\right)$ and $10 \%$ SVMC $\left(y=2^{-5} x, r^{2} 0.76\right)$ with no detectable differences in this relationship for treatment, upper or lower compartment or sampling date.

Measurements of root ethylene production were made using isolated root segments collected from the lower compartment (Table 2). Samples collected on day 9 which by observation was determined as the day when roots first came into contact with the drying soil in the lower chamber (10\% SVMC), despite a lower mean (42\%) with the roots in the drier compartment there was no significant difference, with respect to treatment, in ethylene production rates. The analysis of root $A B A$ concentrations, and root tip dry matter, for roots entering dry soil on Days 9 and 11 after germination are shown in Table 3. Variation with respect to ABA concentration meant that statistically significant differences could not be linked to the observed SVMC differences. The trend was however for $A B A$ to increase with soil drying. ABA concentration did however increase with respect to sampling date by around $20 \%$ for both SVMC treatments, but only when expressed on a 
dry weight basis. SVMC treatment differences were statistically detected on comparing root dry matter content from the dry soil (10\% SVMC) being lower by 19 and $14 \%$ on days 9 and 11 respectively relative to the wet soil (Table 3).

\section{Discussion}

The experimental approach devised here was developed to address questions about the early developmental responses of wheat seedling seminal roots to differences in SVMC. During early root development and seed establishment it is suggested that soil $\psi$ and seedling responses to decreasing soil $\Psi$, are important factors in determining survival and subsequent yield (Lynch, 2011; Ober et al., 2014; Atkinson et al., 2015). The evidence to support the idea that roots and root systems show dry matter allocation plasticity to exploit below ground heterogeneous environments and enhance nutrient uptake is much stronger, than the case for promoting water uptake (Bingham and Bengough, 2003; Mallamy, 2005; Renton and Poot, 2014; Jin et al., 2015). In simple terms, roots have the capacity to locate and exploit soil water by allocating root dry matter to regions where it is more abundant (Lynch, 2013). It is well known, for example, that water deficits, depending at what time they develop, which soil horizon dries, and the location of functional roots, can have a profound influence on plant survival and recovery (Sharp and Davies, 1985; Asseng et al., 1998). Plant breeders are now using this information to develop strategies to improve crop water uptake (Wasson et al., 2012). For example, wheat genotypes are known to have different root system architectures, in particular deeper rooting characteristics, which lead to greater yields and phenotypic traits being exploitated by crop breeders (Ehdaie et al., 2012; Wasson et al., 2012; Ober et al., 2014; Nakhforoosh et al., 2014; White et al., 2015). This is a different strategy than those which focus on increased allocation of dry matter to reproductive structures (Reynolds et al., 2009). It is unlikely that any single 
strategy will enable adaptation to climatic change, particularly, in arid environments, but a focus on root system biology has the potential to optimize resource acquisition where responses to limited access and availability of water are critical.

The experiments reported here show that seminal roots grow at a constant and predictable rate from a region of high SVMC (with soil close to FSWC), into the lower soil column (in the lower compartment), when it is drier. Root exploration occurs in a manner where the proportional allocation of dry matter in the drier soil increases, when roots come into contact with soil at a lower SVMC. But this change in root distribution occurred in the absence of any reduction in the total amount of root (length or dry mass); but a proportional and sequential shift in root production was detected as the soil in the lower compartment dried. Measurements of leaf gas exchange and leaf growth support the notion that carbon acquisition was not reduced in response to roots in contact with drier soil. When the upper and lower SVMC were similar, around $81-85 \%$ of the seminal roots remained in the upper soil, both on a dry weight and length basis. On drying the lower soil compartment to around $10 \%$ SVMC there was a shift in root allocation to around $51-57 \%$ remaining in the upper compartment. The large increase in roots in the lower compartment (from 14-19 to 42 $48 \%$ accounting for weight or length measurements) was consistent in experiments 1 to 4 . The consistency of seminal root response shows that the plasticity of these roots was not due to alterations in the ratio of dry matter to root length which could be perceived as an alteration in root carbon use efficiency. Changes in root morphological features such as the development of cortical aerenchyma that are suggested to improve water uptake along with a reduction in metabolic maintenance were not seen in these seminal roots (Lynch, 2011; Jaramillo et al., 2012). This was not obviously the case in experiment 5, where the root morphology and chemical analyses (Table 3) were derived from analysis of root segments which were smaller and younger than those presented 
in Figure 6. The roots sampled in experiment 5 included only the root tip and the tissues in the region directly behind the root tip (cell expansion zone), which were in the lower compartment. This supports the notion that there are positional differences in a roots structure which we know influence ion and water uptake and this appears to be measurable through difference in dry matter allocation when sampling roots over even short but different developmental, temporal sequences. Other work with wheat shows the apical 3 to $4 \mathrm{~mm}$ region behind the root tip as the site of $A B A$ accumulation (Vysotskaya et al., 2008).

Evidence shows that shoot physiology with respect to leaf growth rate and or gas exchange $(A, E, g)$, remained unchanged when roots grew into soil with a lower SVMC indicating resources (water and nutrients) where being supplied from the upper soil column with its greater SVMC. This was confirmed experimentally when the upper compartment SVMC was allowed to decline. In this situation soil drying delayed the time of the emergence and the growth rate of leaf number 3 relative to seedlings held at a SVMC of $21 \%$. Further drying of the soil, in the lower compartment (to an SVMC of $10 \%)$, reduced the growth rates of later emerging leaves. This shows that seminal roots respond, in a manner which has been documented, to soil drying and this involves root perception of a declining SVMC and the conveying of this information to the shoot, influencing leaf growth and stomatal regulation of gas exchange (Passioura, 1988; Davies et al., 2008). We show in experiment 3 when comparing treatments 2 (T4.8:24) and 3 (T24:11), the drying of the upper compartment (T4.8:24) reduced leaf gas exchange and growth with a concomitant reduction in total root production, but an increased allocation of roots exploiting the wetter lower compartment (34\% for T4.8:24 compared to $6 \%$ in T24:24). This supports our initial notion of the way roots respond through allocation plasticity to enhance access to water. For T24:11 treatment the allocation to root growth to the lower drier compartment was similar to $\mathrm{T} 4.8: 24$ at $26 \%$ where SVMC in the lower 
compartment was higher and similar to T24:24 despite its much lower allocation of total root dry matter (i.e. 6\%). Given the evidence presented here, it does not seem possible that shoot deprivation of nutrients, which often accompanies soil drying, was responsible for the change in root dry matter allocation. Here we do not see predictable leaf responses, such as a decline in leaf growth, photosynthesis or stomatal conductance, as are apparent with nutrient deficiency in wheat (Vysotskaya et al., 2008).

It is apparent from these experiments that roots in the lower compartment soil were exposed to a declining SVMC which has been shown to reduce root $\psi$. Root tissue analysis included sampling material beyond the elongation and root tip zones. While it is well known that despite root tips being exposed to lower soil $\psi$, and experiencing confounding 'anatomical disconnectivity' with respect to root xylem water $\psi$ gradients, they still grow into dry soil (Boyer et al., 2010). The potential contribution of the phloem in supplying, not only photoassimilates, but sufficient water to the root tip has been proposed as a likely explanation for sustained root growth in dry soil (Prichard et al., 2000; Boyer et al., 2010). Here water in the upper compartment could provide seminal roots via phloem transport with water for root growth.

Given that phloem water in roots, derived from the upper compartment, is the most likely means for the continued growth of roots into drying soil; it does not however explain the increased allocation of root dry matter to the lower compartment soil. Suggestions have been proposed that root growth rate is determined by the production and possible balance of several endogenous growth regulators, such as, ABA, ethylene, auxin and GA acting in cross-talking networks (Grossmann and Hansen, 2001; Sharp, 2002; Sharp and LeNoble, 2002; Steffens et al., 2006). Importantly, these authors suggest that ABA may act in limiting ethylene production under drought stress and this may explain why here seminal root growth was maintained when roots come into contact with drying 
soil. It may also explain why we see no evidence of any change in shoot growth or indirectly gas exchange as seen with ABA modulated nutrient deficiency responses in wheat (Vysotskaya et al., 2008).

To explore the possible reasons why seminal roots show different responses to wet and dry soil we measured the concentration of $A B A$ and the production rate of ethylene (an inhibitor of shoot growth) in roots at the time when roots first contacted the drying soil. Our assumption was that this is the point where the root responses (from the root tip) were initiated. In our work, root ethylene production rates did not increase with declining SVMC, or sampling date, which suggests that root ethylene production rate was not influenced by falling SVMC, or that it was being regulated. Despite a clear trend which implies a greater accumulation of ABA with the $10 \%$ SVMC treatment on day 9 and 11 , this difference was not statistically significant due to sample variability. However we do not have evidence which would support an alternative explanation.

\section{Author contributions}

CT carried out the experiments, collected and analyzed the data and drafted the article. CJA helped in running the experiments, collecting and interpreting the data and writing the paper. MAE contributed to the interpretation of data and the editing of the manuscript. All authors contributed to the development and testing of the hypotheses, and to experimental planning and design.

\section{Acknowledgments}

Carlos Trejo wishes to thank the National Council of Science and Technology (CONACYT), Mexico for financial support for a sabbatical year (2014). We are grateful to June Taylor for the root ABA analysis. 


\section{References}

Asseng, S., Ritchie, J.T., Smucker, A.J.M., Robertson, M.J., 1998. Root growth and water uptake during water deficit and recovering in wheat. Plant Soil 201, 265-273.

Atkinson, C.J., Harrison-Murray, R.S., Taylor, J.M., 2008. Rapid flood-induced stomatal closure accompanies xylem sap transportation of root-derived acetaldehyde and ethanol in Forsythia. Environ. Exp. Bot. 64:196-205.

Atkinson, J.A., Wingen, L.U., Griffiths, M., Pound, M.P., Gaju, O., Foulkes, M.J., Le Gouis, J., Griffiths, S., Bennett, M.J., King, J., Wells, D.M., 2015. Phenotyping pipeline reveals major seedling root growth QTL in hexaploid wheat. J. Exp. Bot. 66, 2283-2292.

Bingham, I.J., Bengough, A.G., 2003. Morphological plasticity of wheat and barley roots in response to spatial variation in soil strength. Plant Soil 250, 273-282.

Boyer, J.S., 1982. Plant productivity and environment. Science 218, 443-448.

Boyer, J.S., Silk, W.K., Watt, M., 2010. Path of water for root growth. Func. Plant Biol. 37, 1105-1116.

Davies, W.J., Wilkinson, S., Loveys, B., 2008. Stomatal control by chemical signaling and the exploitation of this mechanism to increase water use efficiency in agriculture. New Phytol. 153, 449-460.

Ehdaie, B., Layne, A.P., Waines, J.G., 2012. Root system plasticity to drought influences grain yield in bread wheat. Euphytica 186, 219-232.

Fábián, A., Jäger, K., Barnabás, B., 2008. Effects of drought and combined drought and heat stress on germination ability and seminal root growth of wheat (Triticum aestivum $\mathrm{L}$ ) seedlings. Acta Biol. Szegediensis 52, 157-159.

Fordham, S.J., Green, R.D., 1980. Soils of Kent Soil Survey Bulletin No. 9. The Soil Survey, Rothamsted Experimental Station, Harpenden, Hertfordshire, UK.

Godfray, H.C., Beddington, J.R., Crute, I.R., Haddad, L., Lawrence, D., Muir, J.F., Pretty, J., Robinson, S., Thomas, S.M., Toulmin, C., 2010. Food security: The Challenge of feeding 9 billion people. Science 327, 812-818.

Grossmann, K., Hansen, H., 2001. Ethylene-triggered abscisic acid: A principle in plant growth regulation? Physiol. Plant 113, 9-14.

Jaramillo, R.E., Nord, E.A., Chimungu, J.G., Brown, K.M., Lynch, J.P., 2013. Root cortical burden influences drought tolerance in maize. Ann. Bot. 112, 429-437. 
Ji, H., Liu, L., Li, K., Xie, Q., Wang, Z., Zhao, X. Li, X., 2014. PEG-mediated osmotic stress induces premature differentiation of the root apical meristem and outgrowth of lateral roots in wheat. J. Exp. Bot. 65, 4863-4872.

Jin, K., Shen, J., Ashton, R.W., White, R.P., Dodd, I.C., Parry, M.A.J., Whalley, W.R., 2015. Wheat root growth responses to horizontal stratification of fertiliser in a water-limited environment. Plant Soil 386, 77-88.

Lynch, J.P., 2011. Root phenes for enhanced soil exploration and phosphorus acquisition: Tools for future crops. Plant Physiol. 156, 1041-1049.

Lynch, J.P., 2013. Steep, cheap and deep: an ideotype to optimize water and $\mathrm{N}$ acquisition by maize root systems. Ann. Bot. 112, 347-357.

Manschadi, A.M., Hammer, G.L., John, T., Christopher, J.T., deVoil, P., 2008. Genotypic variation in seedling root architectural traits and implications for drought adaptation in wheat (Triticum aestivum L.) Plant Soil 303, 115-129.

Manske, G.G.B., Vlek, P.L.G., 2002. Root architecture-wheat as a model plant. Chapter 15 In: Plant Roots-the hidden half, $3^{\text {rd }}$ Edition. Y. Waisel, A. Eshel, T. Beeckman, U. Kafkafi. Marcel Dekker Inc. New York. pp 382-398.

Malamy, J.E., 2005. Intrinsic and environmental response pathways that regulate root system architecture. Plant Cell Environ 28, 67-77.

Nakamoto, T., Oyanagi, A., 1994. The direction of growth of seminal roots of Triticum aestivum L. and experimental modification thereof. Ann. Bot. 73, 363-367.

Nakhforoosh, A., Grausgruber, H., Kaul, H.P., Bodner, G., 2014. Wheat root diversity and root functional characterization. Plant Soil 380, 211-229.

Ober, E.S., Werner, P., Flatman, E., Angus, W.J., Jack, P., Smith-Reeve, L., Tapsell, C., 2014. Genotypic differences in deep water extraction associated with drought tolerance in wheat. Fun. Plant Biol. 41, 1078-1086.

Passioura, J.B., 1988. Root signals control leaf expansion in wheat seedlings growing in drying soil. Aust. J. Plant Physiol. 15, 687-693.

Pritchard, J.H., Winch, S., Gould, N., 2000. Phloem water relations and root growth. Aust. J. Plant Physiol. 27, 539-548.

Ren, Y., He, X., Liu, D., Li, J., Zhao, X., Li, B., Tong, Y., Zhang, A., Li, Z., 2012. Major quantitative trait loci for seminal root morphology of wheat seedlings. Mol. Breed. 30, 139-148. 
Renton, M., Poot, P., 2014. Simulation of the evolution of root water foraging strategies in dry and shallow soils. Ann. Bot. 114,763-778.

Reynolds, M., Foulkes, M.J., Slafer, G.A., Berry, P., Parry, M.A.J., Snape, J.W., Angus, W.J., 2009. Raising yield potential in wheat. J. Exp. Bot. 60, 1899-1918.

Royal Society 2009. Reaping the benefits: Science and the sustainable intensification of global agriculture. Policy document 11/09. ISBN: 978-0-85403-784-1.

Sanguineti, M.C., Li, S., Maccaferri, M., Corneti, S., Rotondo, F., Chiari, T., Tuberosa, R., 2007. Genetic dissection of seminal root architecture in elite durum wheat germplasm. Ann. App. Biol. 151, 291-305.

Sharp, R.E., 2002. Interaction with ethylene: changing views on the role of abscisic acid in root and shoot growth responses to water stress. Plant Cell Environ. 25, 211-222.

Sharp, R.E. Davies, W.J., 1979. Solute regulation and growth by roots and shoots of water-stressed maize plants. Planta 147, 43-49.

Sharp, R.E and Davies, W.J. 1985. Root-growth and water-uptake by maize plants in drying soil. J. Exp. Bot. 36, 1441-1456.

Sharp, R.E. LeNoble, M.E., 2002. ABA, ethylene and the control of shoot and root growth under water stress. J. Exp. Bot. 53, 33-37.

Steffens, B., Wang, J. Sauter, M., 2006. Interactions between ethylene, gibberellin and abscisic acid regulate emergence and growth rate of adventitious roots in deepwater rice. Planta 223, 604612.

Tomlinson, I., 2013. Doubling food production to feed the 9 billion: A critical perspective on a key discourse of food security in the UK. J. Rural Stud., 29, 81-90.

Vysotskaya, L.B., Korobova, A.V., Kudoyarova, G.R., 2008. Abscisic acid accumulation in the roots of nutrient-limited plants: Its impact on the differential growth of roots and shoots. J. Plant Physiol. 165, 1274-1279.

Wasson, A.P., Richards, R.A., Chatrath, R., Misra, S.C., Sai Prasad, S.V., Rebetzke, G.J., Kirkegaard, J.A., Christopher, J., Watt, M., 2012. Traits and selection strategies to improve root systems and water uptake in water-limited wheat crops. J. Exp. Bot. 63, 3485-3498.

White, C.A., Sylvester-Bradley, R., Berry, P.M., 2015. Root length densities of UK wheat and oilseed rape crops with implications for water capture and yield. J. Exp. Bot. 66, 2293-2303.

Zhang, J., Sui, X., Lib, B., Su, B., Li, J., Zhou, D., 1998. An improved water-use efficiency for winter wheat grown under reduced irrigation. Field Crops Res. 59, 91-98. 


\section{Table 1.}

Soil water content expressed as SVMC (\%) and $\psi_{w}$ (MPa) for samples taken from the lower compartment in which plants of Triticum aestivum L. Cv. Redigo Mulika seedlings had been grown for 11 days post germination.

\begin{tabular}{lcccc}
\hline & \multicolumn{2}{c}{ Well-watered control } & \multicolumn{2}{c}{ Drying lower compartment } \\
\hline $\begin{array}{l}\text { Days after } \\
\text { germination }\end{array}$ & $\begin{array}{c}\text { Soil volumetric } \\
\text { water content } \\
(\text { SVMC \%) }\end{array}$ & $\begin{array}{c}\text { Soil water } \\
\text { potential } \\
\left(\Psi_{\mathrm{w}} \mathrm{MPa}\right)\end{array}$ & $\begin{array}{c}\text { Soil volumetric } \\
\text { water content } \\
(\mathrm{SVMC} \%)\end{array}$ & $\begin{array}{c}\text { Soil water } \\
\text { potential } \\
\left(\psi_{\mathrm{w}} \mathrm{MPa}\right)\end{array}$ \\
\hline 7 & $25.3 \pm 1.05$ & $-0.109 \pm 0.057$ & $9.94 \pm 0.11$ & $-0.653 \pm 0.192$ \\
9 & $25.4 \pm 1.09$ & $-0.199 \pm 0.072$ & $9.80 \pm 0.09$ & $-0.634 \pm 0.060$ \\
11 & $26.1 \pm 1.10$ & $-0.156 \pm 0.125$ & $9.75 \pm 0.21$ & $-0.731 \pm 0.109$ \\
\hline
\end{tabular}

Note: No statistically significant differences were detected with respect to SVMC or $\psi_{w}$ or sample date within a treatment. 
Table 2.

Analysis of ethylene (pmol kg-1 $\left.\mathrm{s}^{-1}\right)$ production from the sampled root terminal sections of Triticum aestivum L. CV. Redigo Mulika seedlings grown for 11 days post germination at a constant SVMC in the upper compartment of $20 \%$ and the lower compartment at a SVMC of either 21 or $10 \%$.

\begin{tabular}{lcc}
\cline { 2 - 3 } & Day 9 & Day 11 \\
\hline SVMC (\%) & pmol kg $^{-1} \mathrm{~s}^{-1}$ & $\mathrm{pmol} \mathrm{kg}^{-1} \mathrm{~s}^{-1}$ \\
\hline 21 & $15.85 \mathrm{a}$ & $18.31 \mathrm{a}$ \\
10 & $9.24 \mathrm{a}$ & $20.04 \mathrm{a}$ \\
\hline
\end{tabular}

Note: Data followed by the same letter are not statistically significant, $t$-students $P \leq 0.05$ 


\section{Table 3.}

Analysis of abscisic acid (ng $\mathrm{g}^{-1} \mathrm{fwt}$./dwt.) production from the sampled root terminal sections of Triticum aestivum L. CV. Redigo Mulika seedlings grown for 9 or 11 days post germination at a constant SVMC in the upper compartment of $20 \%$ and the lower compartment at a SVMC of either 21 or $10 \%$.

\begin{tabular}{lcccccc}
\cline { 2 - 6 } & \multicolumn{3}{c}{ Day 9} & \multicolumn{3}{c}{ Day 11} \\
\hline $\begin{array}{l}\text { SVMC } \\
(\%)\end{array}$ & $\begin{array}{c}\text { Root sample } \\
\% \text { dry } \\
\text { matter }\end{array}$ & $\begin{array}{c}\text { ABA } \\
\text { ng g }^{-1} \text { fwt. }\end{array}$ & $\begin{array}{c}\text { ABA } \\
\text { ng g }^{-1} \text { dwt. }\end{array}$ & $\begin{array}{c}\text { Root sample } \\
\% \text { dry } \\
\text { matter }\end{array}$ & $\begin{array}{c}\text { ABA } \\
\text { ng g }^{-1} \text { fwt. }\end{array}$ & $\begin{array}{c}\text { ABA } \\
\text { ng g } \text { dwt. }^{-1}\end{array}$ \\
\hline 21 & 61.3 & 122 & 202 & 52.1 & 135 & 269 \\
10 & 42.3 & 125 & 303 & 38.1 & 138 & 376 \\
\hline F prob. & 0.035 & 0.866 & 0.128 & 0.026 & 0.938 & 0.364 \\
LSD 5\% & 16.86 & 43.7 & 146.4 & 11.7 & 82.8 & 265 \\
\hline
\end{tabular}


Fig 1. The change in relative growth rate $\left(\mathrm{cm} \mathrm{cm}^{-1}\right)$ for leaves 1 to 6 for of Triticum aestivum L. cv. Redigo Mulika seedlings grown for 30 days post germination with a constant SVMC in the upper compartment of $20 \%$ and the lower compartment at a SVMC of $20,17,15,14,13$ or $10 \%$. Leaf growth rates were calculated from the measurement of changes in leaf length.

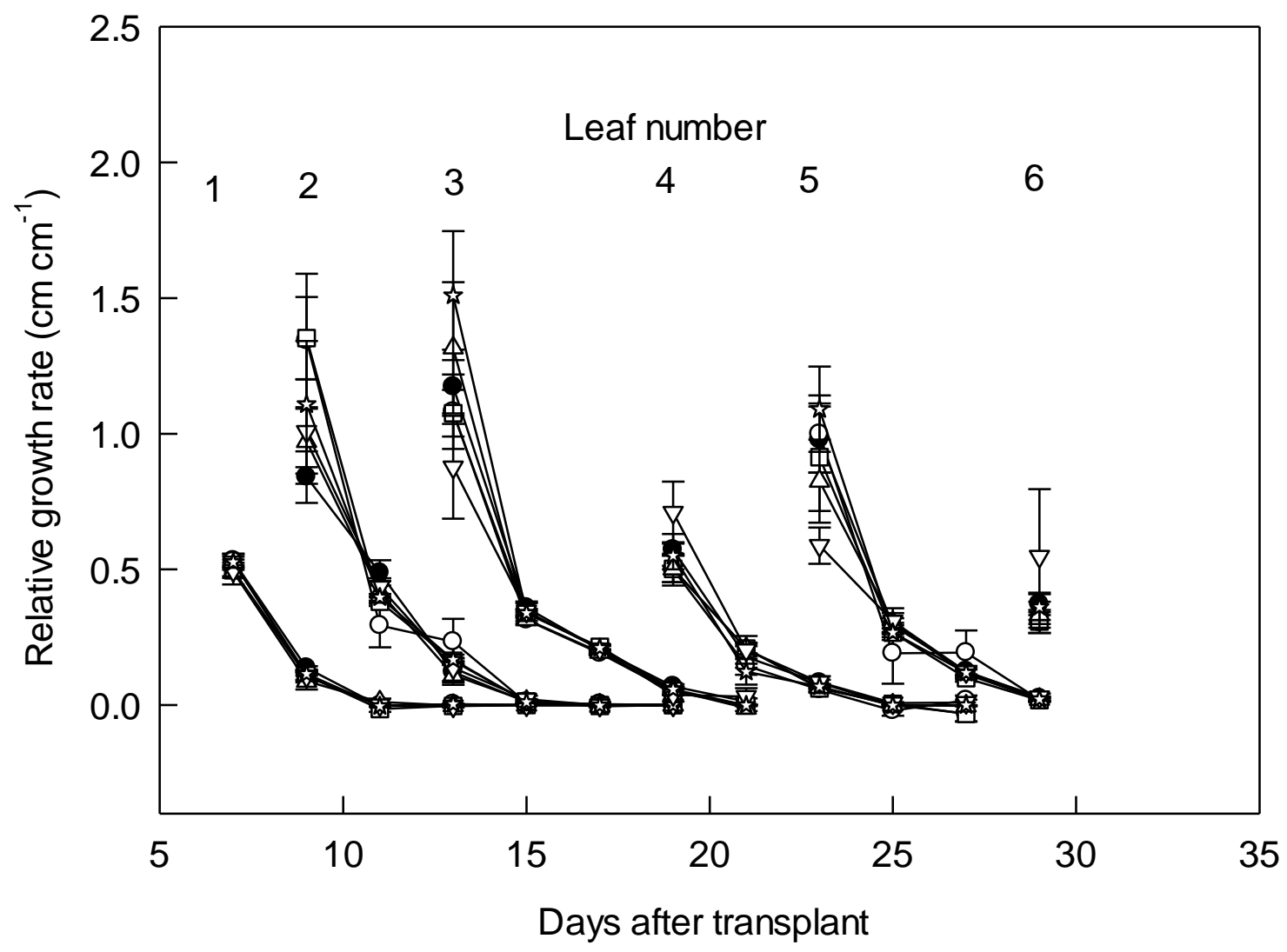

Note: Bars represent the SE of the mean for each data point. SVMC \% in the lower compartment, 20 (O), $17(\bigcirc), 15(\square), 14(\triangle), 13(\nabla), 12(\xi)$. No statistically significant differences were detected with treatment. 
Fig 2. Allocation of root dry matter to upper and lower compartments separated by a Vaseline layer for Triticum aestivum L. CV. Redigo Mulika seedlings grown for 30 days post germination at a constant SVMC in the upper compartment of $20 \%$ and the lower compartment at a SVMC of $20,17,15,14$, 13 or $10 \%$. Numbers shown as percentages in the root dry matter columns above and below the zero line (Vaseline layer) show the proportional distribution of dry matter to the upper and lower compartments at harvest for each treatment.

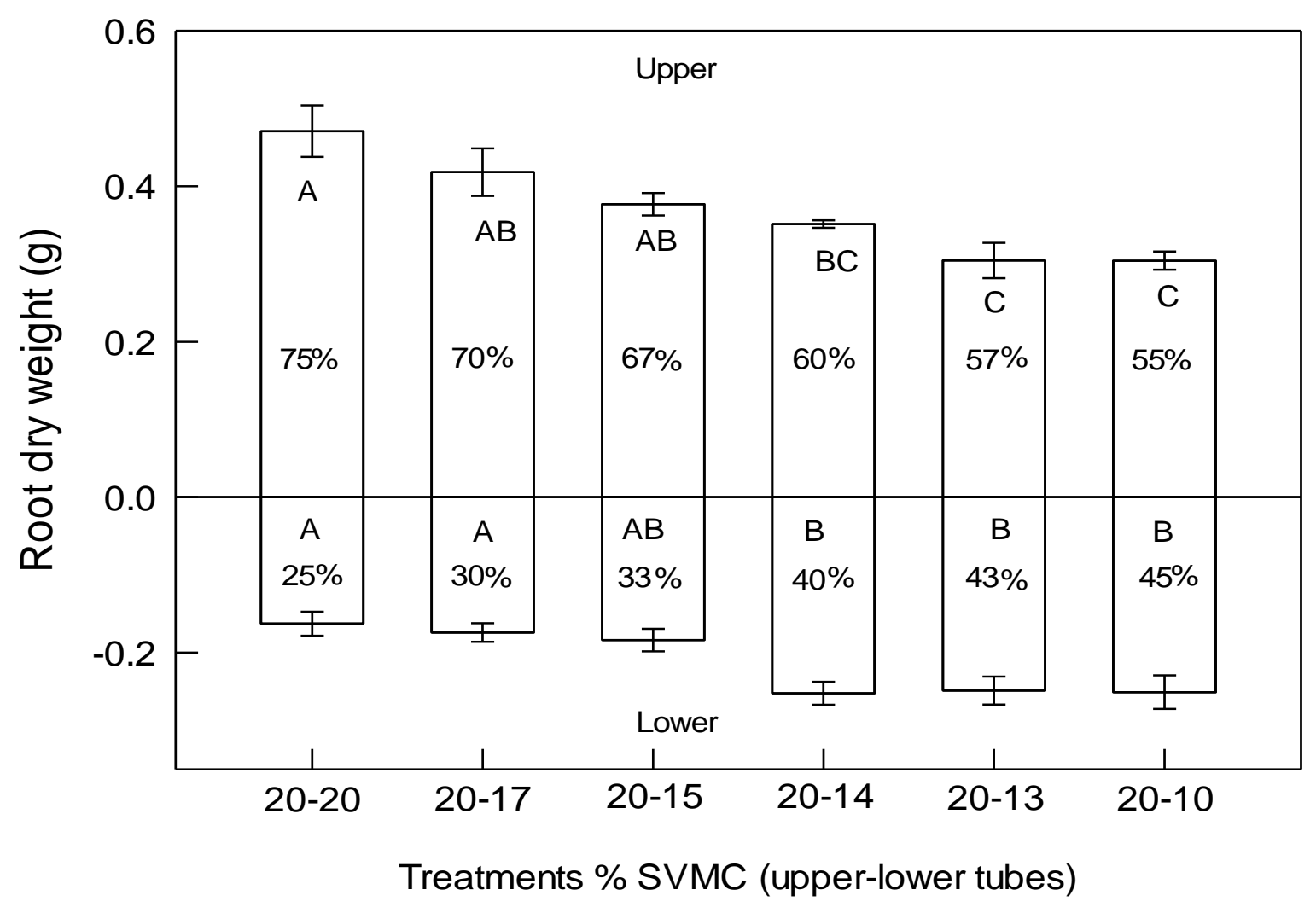

Note: Bars represent the standard error of the mean for each data point. Different letters within the same column represent significant differences within and between treatments at $P=0.05$ by Tukey Test. 
Fig 3. Allocation to root length and root dry matter for upper and lower compartments separated by a Vaseline layer for Triticum aestivum L. cv. Redigo Mulika seedlings grown for 18 days post germination with a constant SVMC in the upper compartment of $21 \%$ and the lower compartment at a SVMC of $18,16,15,14$ or $10 \%$. Numbers shown as percentages in the root dry matter columns above and below the zero line (Vaseline layer) show the proportional distribution of dry matter to the upper and lower compartments at harvest for each treatment.
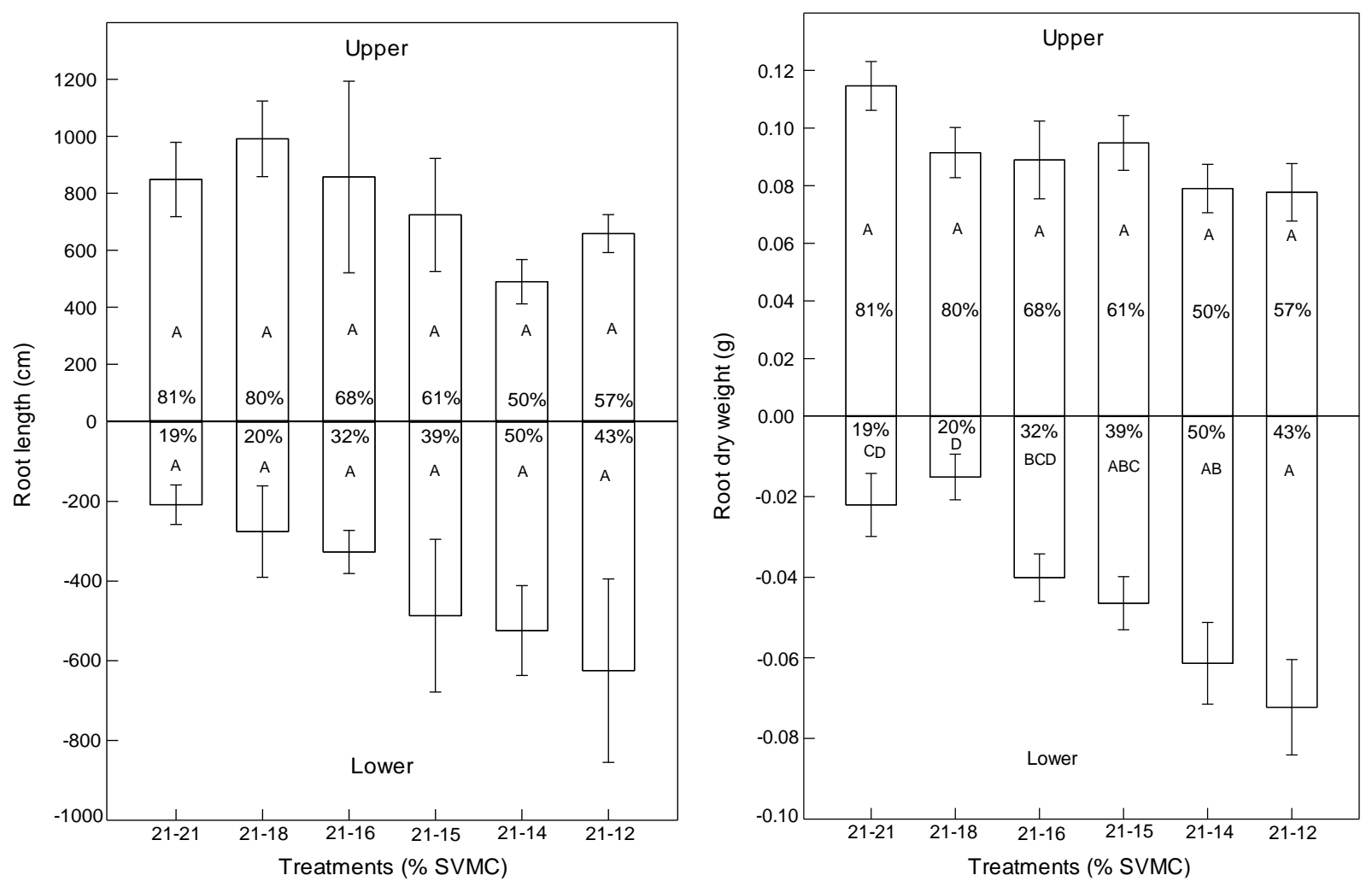

Note: Bars represent the SE of the mean for each data point. Different letters within the same column represent significant treatment differences within and between treatments at $P=0.05$ by Tukey Test. 
Fig 4. Allocation to total root length and total dry matter to upper and lower compartments $(A, B)$ and seminal and nodal roots (C,D) separated by a Vaseline layer for Triticum aestivum L. cv. Redigo Mulika seedlings grown for 18 days post germination. The target SVMC used were as follows: treatment 1, 24\% upper and lower compartments [T24:24]; treatment 2, upper 4.8\% and 24\% lower [T4.8:24] and treatment 3, upper compartment $24 \%$ and the lower $11 \%$ [T24:11].
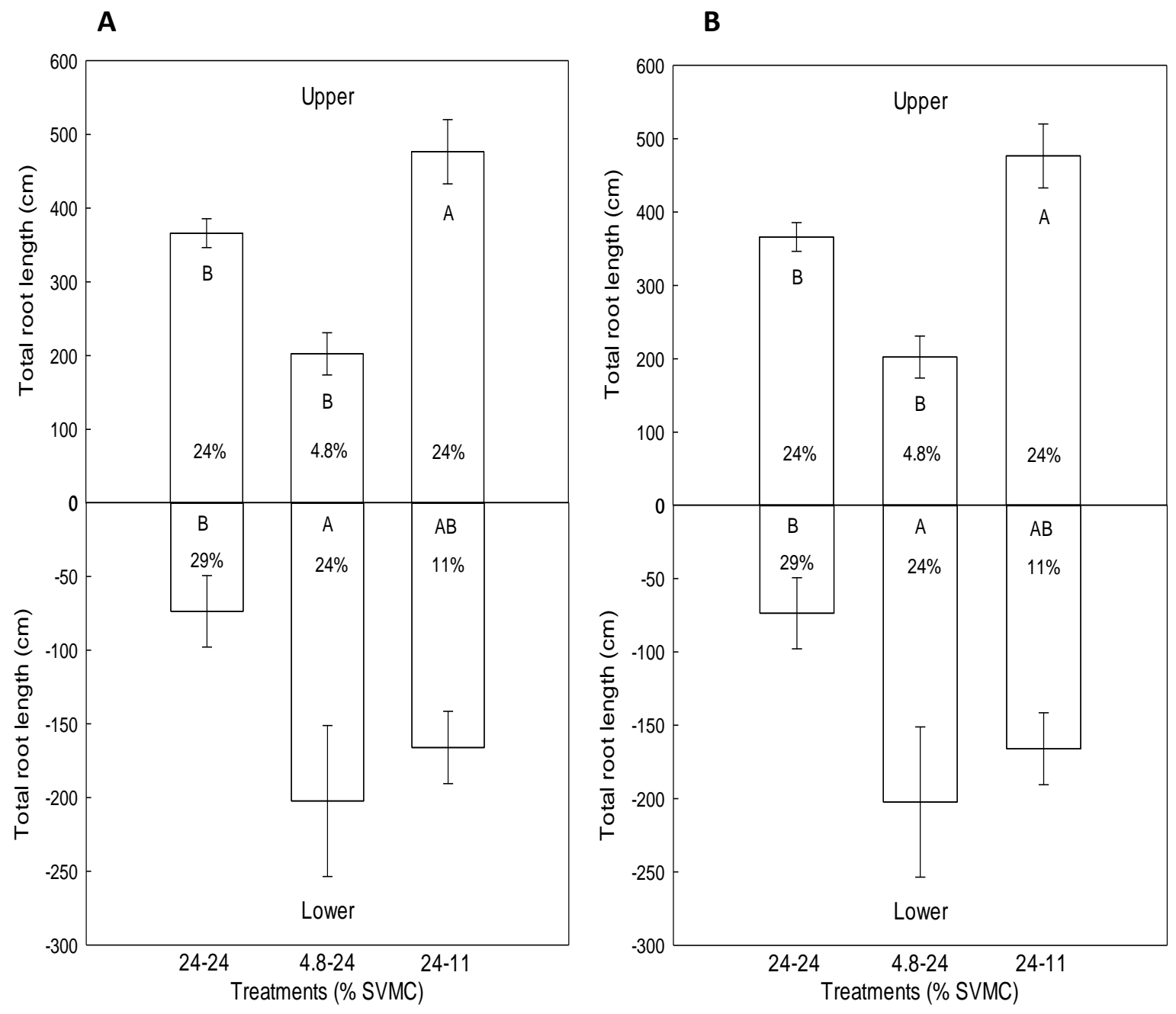
Fig 4. Continued

C

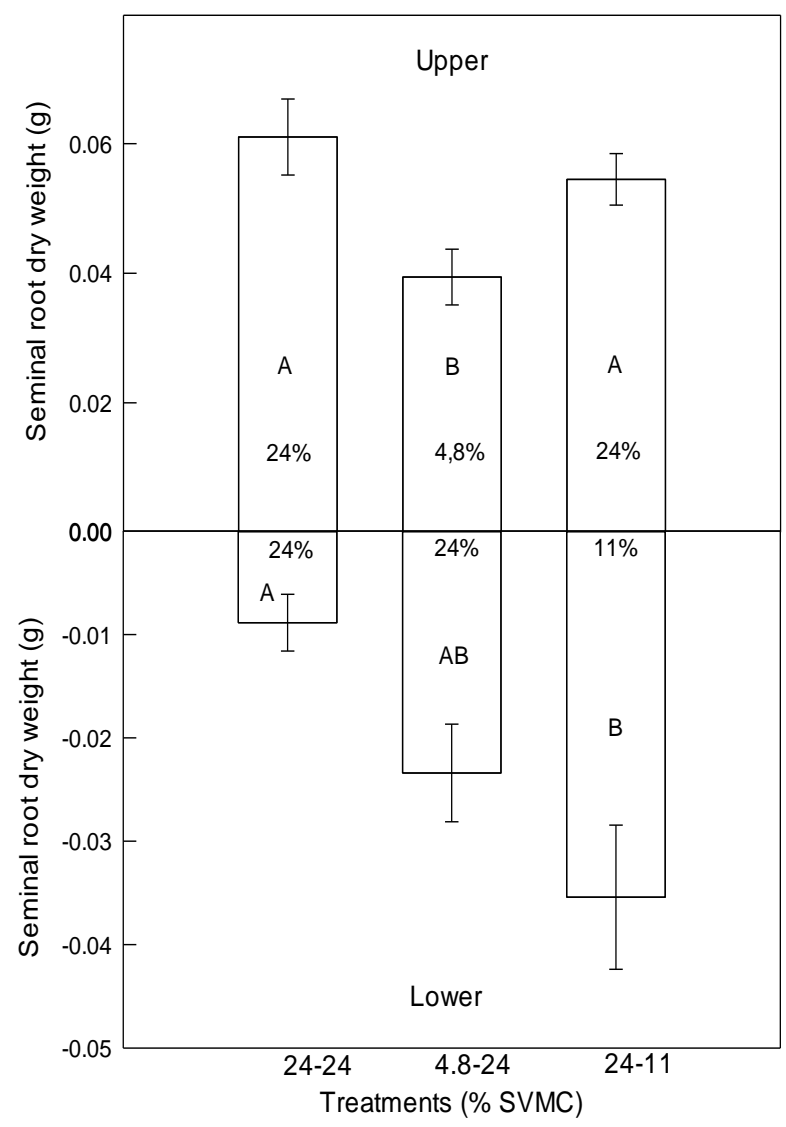

D

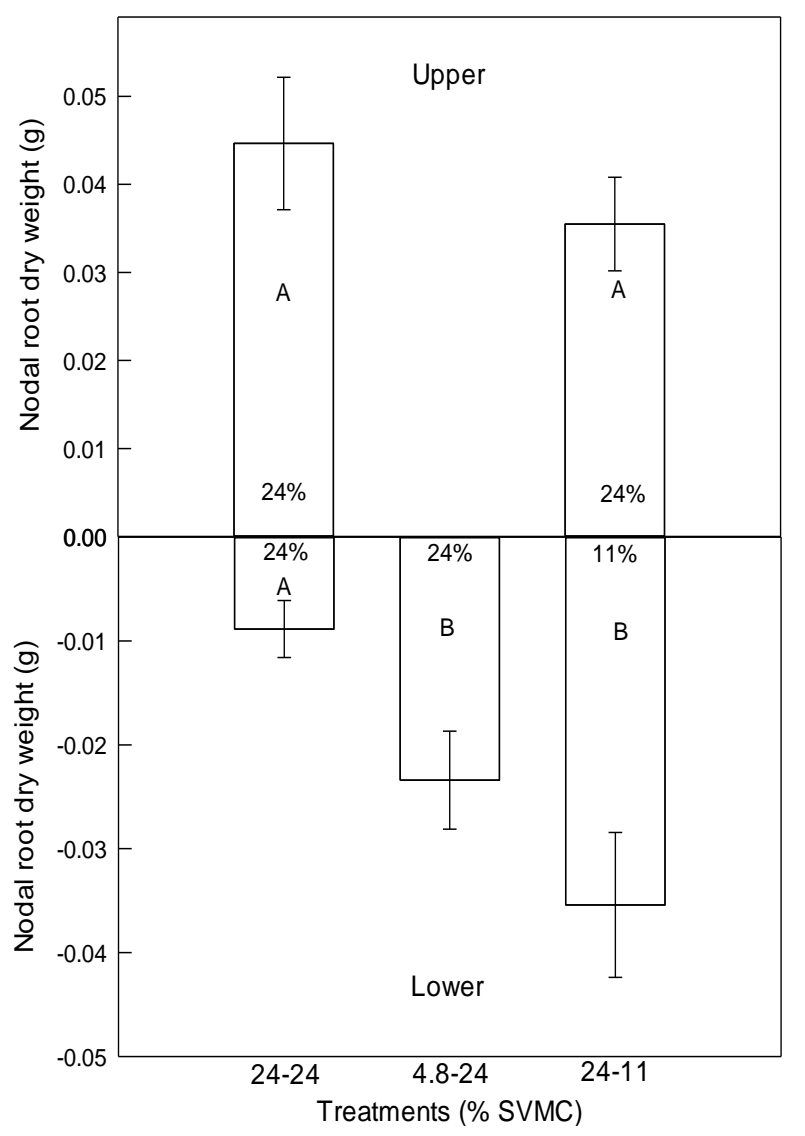

Note: Bars represent the SE of the mean for each data point. Numbers in shown in upper and lower compartments in the columns reflect the mean SVMC at harvest for each treatment. Different letters within the same column represent significant differences within and between treatments at $P=0.05$ by Tukey Test. 
Fig 5. The pattern of leaf extension rate changes for leaves 1 to 4 for Triticum aestivum L. cv. Redigo Mulika seedlings grown for 18 days post germination when subjected to similar SVMC in the upper and lower compartments (T24:24), drying in the upper compartment with a constant SVMC in the lower compartment (T4.8:24) and an upper compartment SVMC, as in T24:24, but a declining lower compartment SVMC (T24:11).

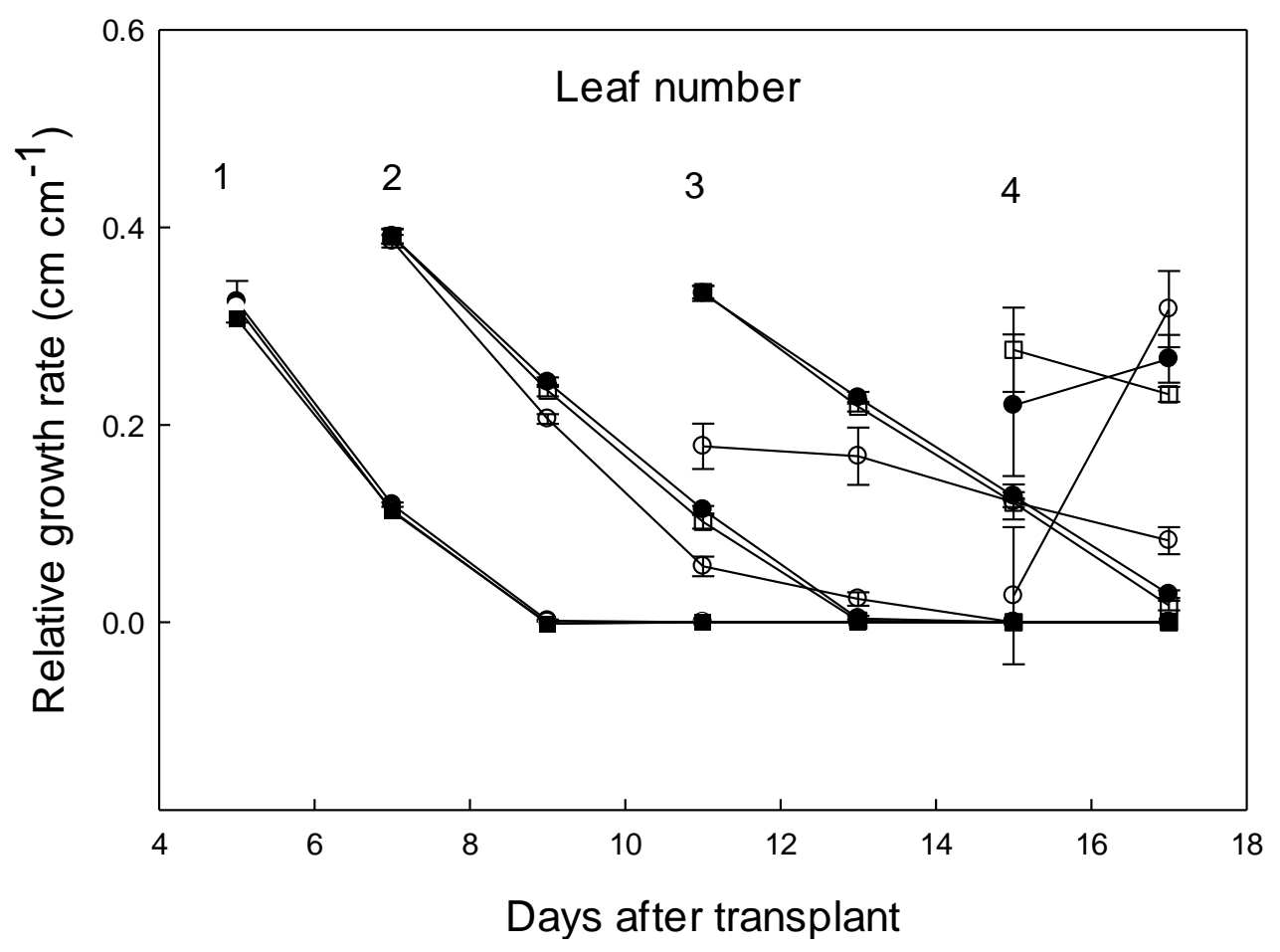

Note: Bars represent the SE of the mean for each data point. The treatments are coded as follows: T24:24 (•); T4.8:24 (O); T24:11 (口). 
Fig 6. Allocation to root length and root dry matter to the upper and lower compartments separated by a Vaseline layer for of Triticum aestivum L. cv. Redigo Mulika seedlings grown for 20 days post germination with at a constant SVMC in the upper compartment of $24 \%$ and the lower compartment at a SVMC of 14,12 or $10 \%$.
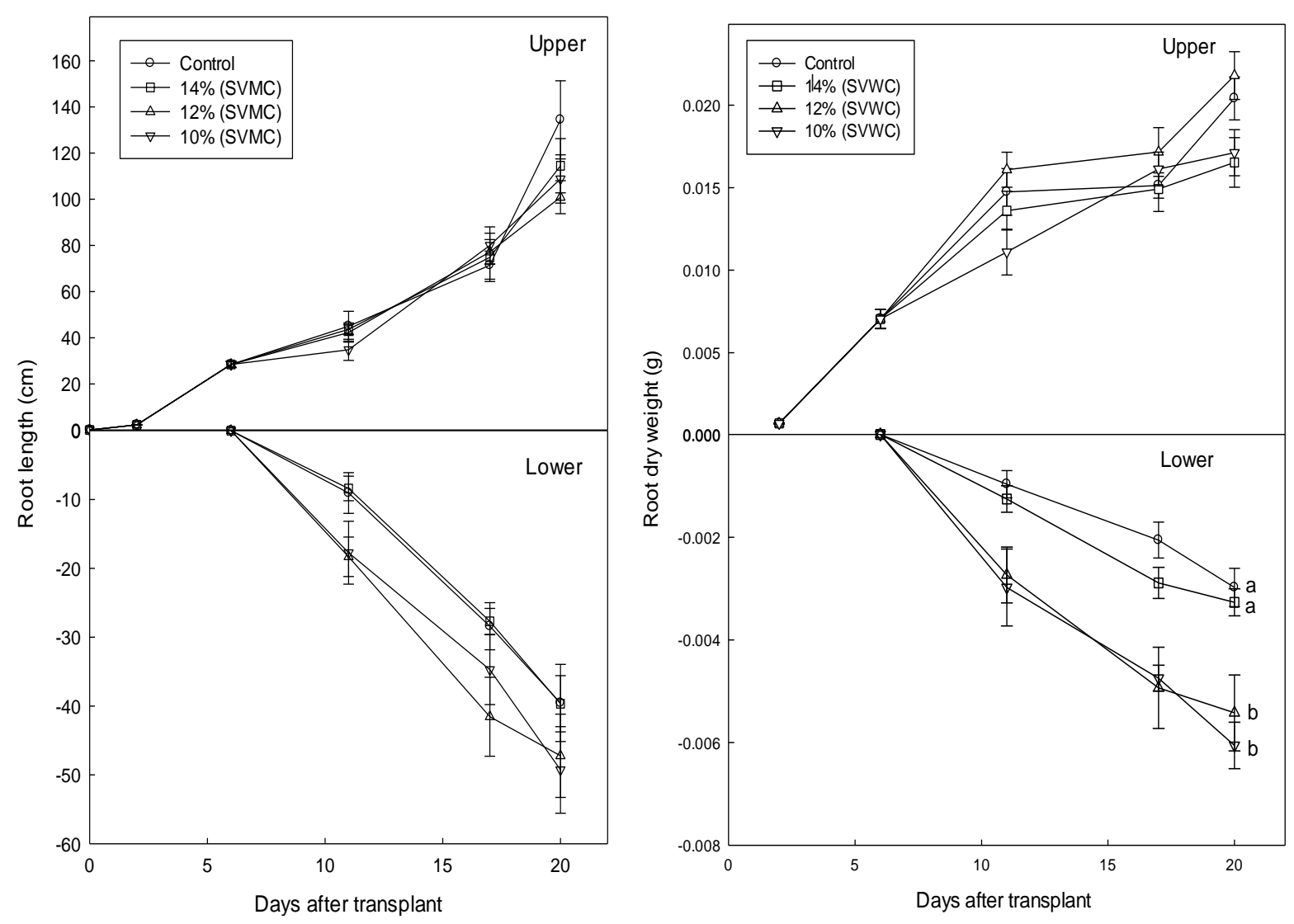

Note: Bars represent the SE of the mean for each data point. Different letters at the same sampling point reflect significant differences between treatments at $P=0.05$ by Tukey Test. 
Fig 7. The changes in root and soil water potentials $(\psi, \mathrm{MPa})$ from measurement of the lower compartment, allowed to dry to different SVMC, for plants of Triticum aestivum L. cv. Redigo Mulika seedlings grown for 20 days post germination at a constant SVMC in the upper compartment of $24 \%$ and the lower compartment at a SVMC of 14,12 or $10 \%$.

Days after transplant
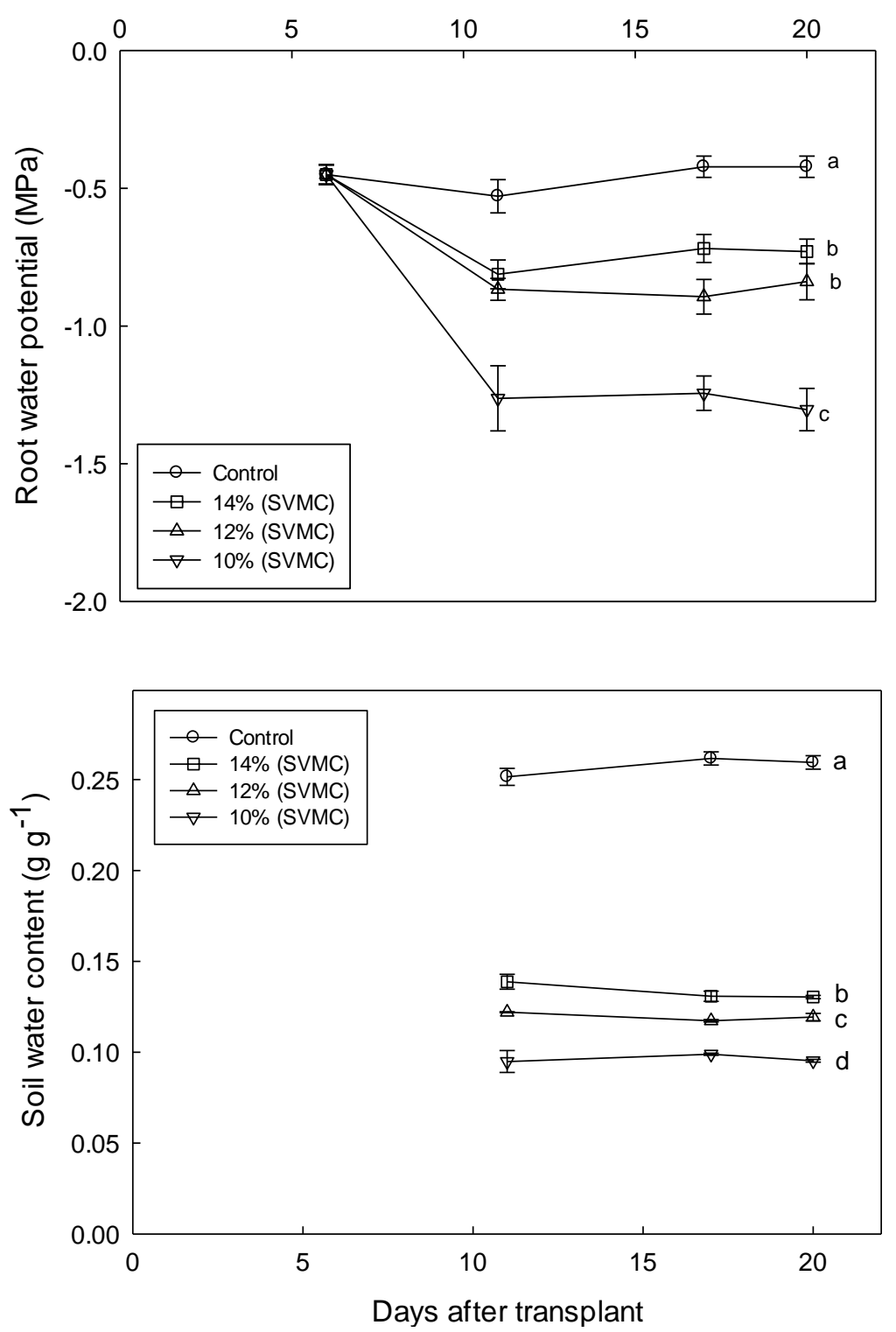

Note: Bars represent the SE of the mean for each data point. Different letters at the same sampling point reflect significant treatment differences at $P=0.05$ by Tukey Test. 
Fig 8. Allocation of root length and dry matter to upper and lower compartments separated by a Vaseline layer for of Triticum aestivum L. cv. Redigo Mulika seedlings grown for 11 days post germination at a constant SVMC in the upper compartment of $24 \%$ and the lower compartment at either a SVMC of $24 \%$ or $10 \%$.
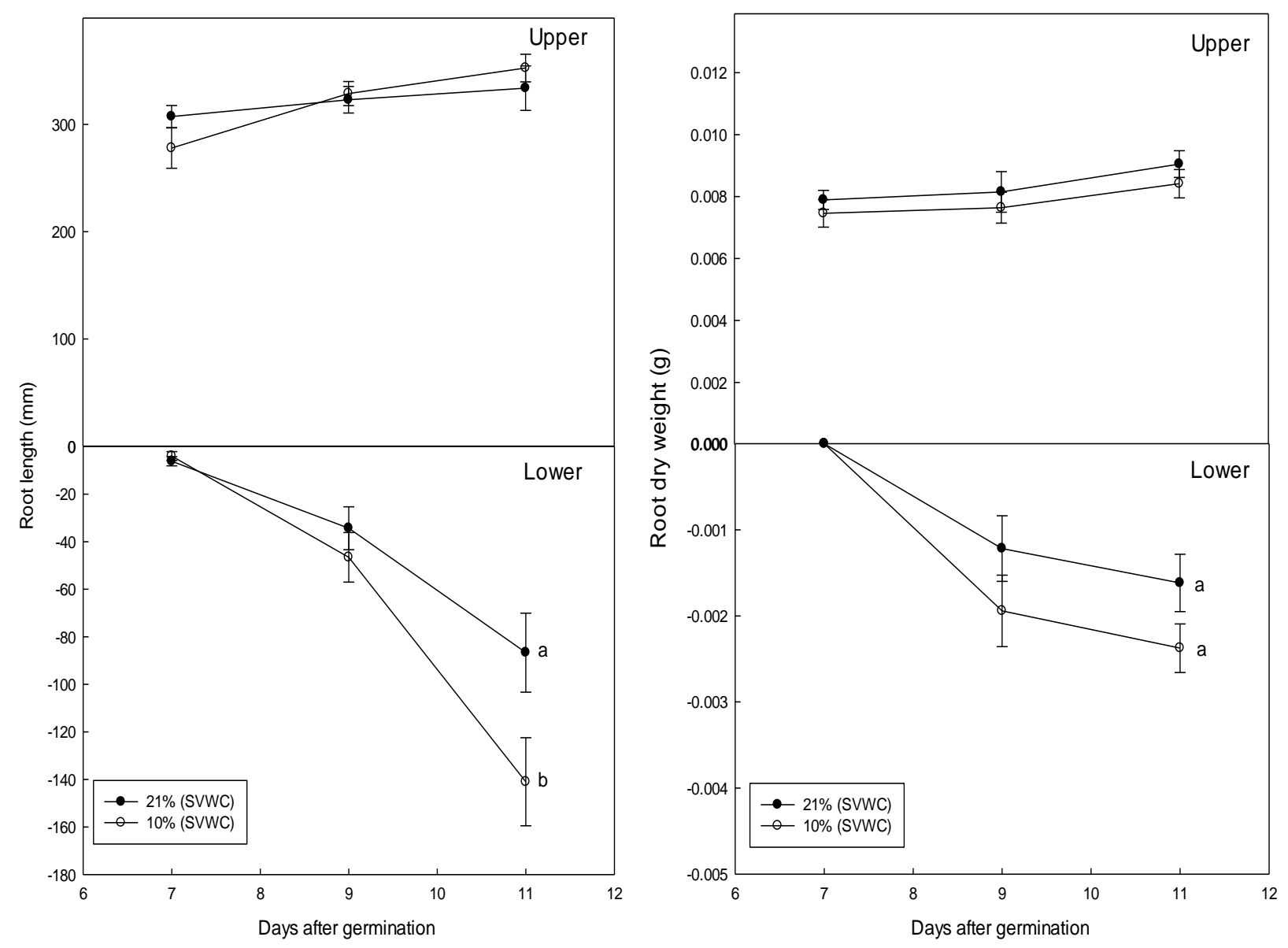

Note: Bars represent the SE of the mean for each data point. Different letters at the same sampling point reflect significant treatment differences at $P=0.05$ by Tukey Test. 